\title{
Risk of Seizure Recurrence after Withdrawal of Antiepileptic Drugs in Multiply Handicapped Egyptian Children with Epilepsy
}

\author{
Nabil Kitchener*1, Nilly Nagy ${ }^{1}$, Naema Michael ${ }^{1}$, Mohamed Helmy ${ }^{1}$ and Samia Aziz ${ }^{2}$ \\ ${ }^{1}$ Departments of Neuropsychiatry, El-Mataryia Teaching Hospital, Egypt \\ ${ }^{2}$ Child Mental Health-Medical Studies, Ain Shams University, Egypt
}

*Corresponding author: Nabil Kitchener, Departments of Neuropsychiatry, ElMataryia Teaching Hospital, EGOTHI, Egypt.

Received Date: December 19, 2019

Published Date: January 14, 2020

\begin{abstract}
Objectives: To determine the incidence and risk factors of seizure recurrence in multihandicapped Egyptian children with epilepsy after withdrawal of antiepileptic drugs (AEDs).

Methods: This was a prospective study from January 1995 to January 2016. The study population was multihandicapped children with epilepsy followed up in the outpatient clinic of Centre for Children with Special Needs; Egyptian Integrated Care Association (CCSN; EICA), Cairo, Egypt. The eligible children were less than 13 years, seizure-free for at least 24 months, with two normal EEG records, separated by 6 months. The AEDs were withdrawn slowly. The patients were then followed up to look for seizure recurrence.

Results: One hundred sixty-two children were recruited in the study. The average age of onset of epilepsy was 14 months. Most patients had partial seizures (49\%). Most were controlled on monotherapy (64.2\%), and were treated with Phenytoin (24\%), Carbamazepine (20.4\%), and Sodium valproate $(16 \%)$. The seizure free duration before starting to withdraw AED was $48.3 \pm 9$ months. None of the patients had seizure recurrence while the AEDs were being tapered. There were 77 patients (47.5\%) with seizure recurrence. The average duration of follow-up for the patients who did not have seizure recurrence was $45 \pm 3$ months. Most of recurrences occurred in the first twelve months, remainder during next twelve months. The risk factors of seizure recurrence were abnormal neurological examination, the need for use of polytherapy, presence of abnormal findings on brain imaging (CT and/or MRI).
\end{abstract}

Conclusion: Risk of seizure recurrence after AED withdrawal in multiply handicapped Egyptian children was high at 47.5\%.

\section{Introduction}

Seizure is a common neurological disorder in children [1,2]. Antiepileptic drugs (AEDs) are usually used for long-term. The medication is only tapered after a seizure-free interval to minimize the risk of recurrence $[3,4]$. There are many studies on the risk of seizure recurrence after withdrawal of AEDs, which varies from $10 \%$ to $50 \%$, partly depending on the study designs [3-7]. The risk factors of seizure recurrence identified include older age of onset of epilepsy, remote symptomatic epilepsy, abnormal electroencephalography (EEG), some epilepsy syndromes such as juvenile myoclonic epilepsy, severity of epilepsies, and those with family history [8-15]. There are to date only rare reports on risk of seizure recurrence after AED withdrawal in Egypt. The objectives of this study were to determine the incidence and risk factors of seizure recurrence in multihandicapped Egyptian children with epilepsy after withdrawal of antiepileptic drugs (AEDs).

\section{Methods}

This was a prospective study from January 1995 to January 2016. The study population was Egyptian multihandicapped children with epilepsy followed up in the outpatient clinic of Centre for Children with Special Needs; Egyptian Integrated Care Association (CCSN; EICA), Cairo, Egypt. The eligible children were less than 13 years, seizure-free for at least 24 months, with two normal EEG records, separated by 6 months. All patients were subjected 
to thorough clinical examination, EEG records, and brain imaging (CT and/or MRI). The AEDs were withdrawn slowly. The exact duration, over which the AEDs were withdrawn, however, varied among the patients, based on the joint decision of the attending physicians, parents, and the patients. If the patients were receiving more than one AEDs, the AEDs were withdrawn sequentially with each AED being withdrawn over at least 3 months. After total drug withdrawal, the patients were then followed up to look for seizure recurrence.

\section{Statistical Analysis}

A survival analysis was performed with seizure recurrence as the hazard ratio and the interval of seizure recurrence (failure time) start after complete drug withdrawal. Log rank test was used for univariate analysis and Cox proportional-hazard model was used for multivariate analysis for risk factors of seizure recurrence. All statistical tests were 2-tailed. The p-value of less than 0.05 was regarded as statistically significant.

\section{Results}

A total of 162 patients (85 Males and 77 Females), selected from population of 7568 patients, were enrolled in this study, which was from January 1995 to January 2016. The characteristics of patients are shown in Table 1.

Table 1: Characteristic of the patients with AED withdrawal $(n=162)$.

\begin{tabular}{|c|c|c|}
\hline & Characteristic & No of Patients (\%) \\
\hline 1 & Male: Female & $85: 77$ \\
\hline 2 & Age at onset of epilepsy in months & 14 (range 4-39 Ms) \\
\hline 3 & $\begin{array}{c}\text { Types of seizures } \\
\text { a. generalized }\end{array}$ & $68(41.9 \%)$ \\
\hline & b. partial & $80(49 \%)$ \\
\hline 4 & c. undetermined & $14(8.6 \%)$ \\
\hline & $\begin{array}{c}\text { Antiepileptic drug (AED) } \\
\text { a. Phenytoin }\end{array}$ & $39(24 \%)$ \\
\hline & b. Carbamazepine & $33(20.4 \%)$ \\
\hline & c. Sodium valproate & $26(16 \%)$ \\
\hline 5 & d. others & $6(3.7 \%)$ \\
\hline 6 & $\begin{array}{c}\text { Seizure-free duration before starting to } \\
\text { withdraw AED in months }\end{array}$ & $48.3 \pm 9($ range $36-64)$ \\
\hline
\end{tabular}

As shown, the average age at onset of epilepsy was 14 months (range 4-39 Ms). The most common seizure was partial (49\%). Most patients were treated with monotherapy (64.2\%). Phenytoin, Carbamazepine and Sodium Valproate were the AED used (24 $\%, 20.4 \%$ and $16 \%$ respectively). Seizure-free mean duration before starting to withdraw AED in months was 48.3 months (range 36-64).

Disabilities in the study group were cerebral palsy (CP) in 47 patients (Spastic quadriparesis CP in 8, Spastic hemiparesis CP in 12, Spastic paraparesis CP in 13, Attaxic CP in 6 and Choreoathetotic $\mathrm{CP}$ in 8), mental retardation in 129 patients, sensory deficits in 20 patients and behavioral disturbances in 38 patients (Table 2).
Table 2: Frequency of types of disability in the 162 patients and its percentage.

\begin{tabular}{|c|c|c|}
\hline Group & No of Patients & $\begin{array}{c}\text { Prevalence of } \\
\text { Specified Disability }\end{array}$ \\
\hline Total study group & 162 & \\
\hline Cerebral Palsy (CP) & 47 & $29 \%$ \\
\hline Spastic quadriparesis CP & 8 & $4.9 \%$ \\
\hline Spastic hemiparesis CP & 12 & $7.4 \%$ \\
\hline Spastic paraparesis CP & 13 & $8 \%$ \\
\hline Attaxic CP & 6 & $3.7 \%$ \\
\hline Choreoathetotic CP & 8 & $4.9 \%$ \\
\hline Mental Retardation & 129 & $79.6 \%$ \\
\hline Behavioral Disturbances & 38 & $23.5 \%$ \\
\hline Sensory deficits & 20 & $12.3 \%$ \\
\hline
\end{tabular}

Proposed factors associated with development of epilepsy in the study group include neonatal seizures in 78 patients, positive family history in 47 patients, computerized tomography (CT) brain scanning abnormalities in 99 patients and magnetic resonance brain imaging (MRI) abnormalities in 126 patients (Table 3).

Table 3: Proposed factors associated with development of epilepsy in the study group.

\begin{tabular}{|c|c|c|}
\hline & Epileptic $(\mathbf{n = 1 6 2})$ & Percentage \\
\hline Female/Male & $77 / 85$ & \\
\hline Neonatal seizures & $78 / 162$ & $48 \%$ \\
\hline Positive family history & $47 / 162$ & $29 \%$ \\
\hline MRI abnormalities & $126 / 162$ & $77.8 \%$ \\
\hline CT scan abnormalities & $99 / 162$ & $61.1 \%$ \\
\hline
\end{tabular}

The average duration of follow-up for the patients who did not have seizure recurrence was $45 \pm 3$ months. None of the patients developed seizure recurrence while the AEDs were being tapered. There were 77 patients (47.5\%) who developed seizure recurrence after AED withdrawal. The incidence density was 0.010 person/ months. Most of recurrences occurred in the first twelve months, remainder during next twelve months. The average interval after AED withdrawal when seizure recurrence occurred was $8 \pm 11$ months (range 2-23 months). Most of those with seizure recurrence had partial seizures. The details of patients with seizure recurrence are shown in Table 4.

Univariate analysis was performed for risk factors of seizure recurrence as shown in Table 5. The risk factors for seizure recurrence are patients who required polytherapy, suffer neurological deficits, and have brain imaging, either CT or MRI, abnormalities. Multivariate analysis was also performed for risk factors of seizure recurrence as shown in Table 6, patients who needed polytherapy for control of their seizures had significant risk of recurrence with hazard ratio of 4.22 when compared to those controlled with monotherapy. Table 6 shows, also, that patients suffering neurological deficits had significant risk of recurrence with hazard ratio of 5.71, and patients with CT or MRI, abnormalities had significant risk of recurrence with hazard ratio of 2.9 Table 5 \& 6 . 
Table 4: Characteristic of patients with seizure recurrence ( $n=77$ cases).

\begin{tabular}{|c|c|c|c|c|c|c|c|c|}
\hline हैं & $\begin{array}{c}\text { No of } \\
\text { patients }\end{array}$ & $\begin{array}{l}\text { Percent } \\
\text { of total }\end{array}$ & $\begin{array}{l}\text { Types of } \\
\text { seizure }\end{array}$ & AED & EEG & $\begin{array}{c}\text { Seizure-free } \\
\text { duration (months)* }\end{array}$ & $\begin{array}{l}\text { Recurrence duration } \\
\text { (months)** }\end{array}$ & Other associate \\
\hline \multirow[t]{6}{*}{1} & 31 & $19.1 \%$ & Gen & & NAD & & & $\begin{array}{c}\text { CT and/or MRI abn } \\
\text { in } 20\end{array}$ \\
\hline & 5 & & & PHT & NAD & 38 & $6-12$ & $\mathrm{CT}$ and/or MRI abn in 3 \\
\hline & 4 & & & Carb & NAD & 42 & $2-4$ & \\
\hline & 3 & & & VPA & NAD & 44 & $3-6$ & \\
\hline & 1 & & & Others & NAD & 39 & 8 & \\
\hline & 18 & & & Polytherapy & NAD & $50-52$ & $2-14$ & $\begin{array}{c}\text { CT and/or MRI abn } \\
\text { in } 17\end{array}$ \\
\hline \multirow[t]{6}{*}{2} & 40 & $24.7 \%$ & Part & & NAD & & & $\begin{array}{c}\mathrm{CT} \text { and/or MRI abn } \\
\text { in } 24\end{array}$ \\
\hline & 6 & & & PHT & NAD & 47 & 3 & \\
\hline & 0 & & & Carb & & & & \\
\hline & 5 & & & VPA & NAD & 60 & $2-12$ & CT and/or MRI abn in 2 \\
\hline & 3 & & & Others & NAD & 58 & & \\
\hline & 26 & & & Polytherapy & NAD & $55-64$ & $4-23$ & $\begin{array}{l}\text { CT and/or MRI abn } \\
\text { in } 22\end{array}$ \\
\hline \multirow[t]{6}{*}{3} & 6 & $3.7 \%$ & Undet & & NAD & & & CT and/or MRI abn in 3 \\
\hline & 1 & & & PHT & NAD & 37 & 2 & \\
\hline & 1 & & & Carb & NAD & 42 & 6 & \\
\hline & 0 & & & VPA & & & & \\
\hline & 0 & & & Others & & & & \\
\hline & 4 & & & Polytherapy & NAD & $50-64$ & $4-18$ & CT and/or MRI abn in 3 \\
\hline
\end{tabular}

*Seizure-free duration before commencing AED withdrawal

${ }^{* *}$ Interval after AED withdrawal when seizure recurrence occurred

$\mathrm{AED}=$ antiepileptic drug, Gen = generalized seizures, Part= partial, Undet= undetermined $\mathrm{PHT}=$ phenytoin,

VPA = valproic acid, Carb= Carbamazepine FC = febrile convulsions, EEG = electroencephalography, NAD = no abnormality detected, MRI abn= Magnetic Resonance Imaging Abnormality.

Table 5: Univariate analysis by Log rank test for risk factors of seizure recurrence.

\begin{tabular}{|c|c|c|c|c|c|c|}
\hline & Variable & Total No & Recurrence No & $\%$ of 77 recurrence & Incidence rate & p-value Significance \\
\hline 1 & Male & 85 & 43 & 55.8 & 0.011 & \multirow{2}{*}{ Non Significant } \\
\hline 2 & Female & 77 & 34 & 44.1 & 0.009 & \\
\hline 3 & Generalized seizure & 68 & 31 & 40.2 & 0.010 & \multirow{2}{*}{ Non Significant } \\
\hline 4 & Partial seizure & 80 & 40 & 51.9 & 0.011 & \\
\hline 5 & Undetermined & 14 & 6 & 7.7 & 0.009 & \\
\hline 6 & AED monotherapy & 104 & 29 & 37.6 & 0.006 & \multirow{2}{*}{$\begin{array}{c}\text { Significant } \\
0.001\end{array}$} \\
\hline 7 & 2 AEDs polytherapy & 58 & 48 & 62.3 & 0.018 & \\
\hline 8 & Neonatal seizures & 78 & 17 & 22.1 & 0.004 & \multirow{2}{*}{ Non Significant } \\
\hline 9 & Positive family history & 47 & 9 & 11.6 & 0.004 & \\
\hline 10 & Neurological deficits & 67 & 59 & 76.6 & 0.019 & \multirow{2}{*}{$\begin{array}{c}\text { Significant } \\
0.001\end{array}$} \\
\hline 11 & No Neurological deficits & 95 & 18 & 23.4 & 0.004 & \\
\hline 12 & MRI abnormalities & 126 & 47 & 61 & 0.008 & \multirow{2}{*}{$\begin{array}{c}\text { Significant } \\
0.01 \\
\end{array}$} \\
\hline 13 & No MRI abnormalities & 36 & 6 & 7.8 & 0.003 & \\
\hline 14 & CT scan abnormalities & 99 & 32 & 41.6 & 0.007 & \multirow{2}{*}{$\begin{array}{c}\text { Significant } \\
0.01\end{array}$} \\
\hline 15 & No CT scan abnormalities & 63 & 8 & 10.4 & 0.002 & \\
\hline
\end{tabular}


Table 6: Multivariate analysis by Cox proportional-hazard model for the risk factor of seizure recurrence.

\begin{tabular}{|c|c|c|c|c|}
\hline \multicolumn{2}{|c|}{ Variable } & $\begin{array}{c}\text { Hazard } \\
\text { ratio }\end{array}$ & $\mathbf{9 5 \%}$ CI & P-value / Significance \\
\hline 1 & Polytherapy & 4.22 & $1.6-19.4$ & Highly Significant \\
\hline 2 & $\begin{array}{c}\text { Neurological } \\
\text { deficits }\end{array}$ & 5.71 & $1.3-23.5$ & Highly Significant \\
\hline 3 & $\begin{array}{c}\text { CT or MRI, } \\
\text { abnormalities. }\end{array}$ & 2.90 & $2.6-15.2$ & 0.001 \\
\hline 4 & $\begin{array}{c}\text { Age at onset of } \\
\text { epilepsy }\end{array}$ & 0.99 & $0.99-1.06$ & Non-Significant \\
\hline 5 & $\begin{array}{c}\text { Partial seizures } \\
6\end{array}$ & $\begin{array}{c}\text { Seizure free } \\
\text { interval }\end{array}$ & 1.04 & $\begin{array}{c}0.07- \\
13.67\end{array}$ \\
\hline 7 & Female & 0.86 & $018-2.91$ & Non-Significant \\
\hline
\end{tabular}

\section{Discussion}

Risk of seizure recurrence after AED withdrawal in the study group of multiply handicapped Egyptian children was $47.5 \%$ in accordance with many international published materials. There is a number of characteristics in our cohort, which may explain the higher rate of seizure recurrence. Our patients consist of multiply handicapped, with average age of onset of epilepsy of 14 months, frequent neurological deficits (41\%), and abnormal brain imaging. Children, with those characteristics, have been shown to have guarded prognosis after AED withdrawal15. The proportion with neurological deficits in our cohort is relatively high at $41 \%$. For example, the proportion with neurological deficit in the MRC trial was 22-24\%.9 Remote symptomatic epilepsy, presence of neurological deficits particularly mental retardation, have been shown to be associated with poorer prognosis [8-16]. The average seizure free duration before commencing AED withdrawal in our patients is 48.3 months, which is relatively long. Longer period of seizure freedom before AED withdrawal is associated with lower seizure recurrence $[7,17]$. In this study, we found that patients with polypharmacy had the risk of seizure recurrence four times more than monotherapy. Not surprisingly, patients who needed polypharmacy reflect their disease being more severe than those requiring monotherapy. We found that patients with neurological deficits had the risk of seizure recurrence more than five times more than who suffer no neurological deficits. Not surprisingly, patients who suffer neurological deficits reflect their disease being anatomical and more severe than those without anatomical lesions. We could not find types of seizure, age at onset of epilepsy, sex, and seizure-free interval during medication as risk factors of recurrence which are different from previous studies [8-12,18]. EEG abnormalities which have been shown to be a risk factor of recurrence 10 were excluded from our group as we put an inclusion criteria that the eligible children were less than 13 years, seizurefree for at least 24 months, with two normal EEG records, separated by 6 months.

\section{Conclusion}

Risk of seizure recurrence after AED withdrawal in multiply handicapped Egyptian children, in this study, was high at $47.5 \%$.

\section{Acknowledgement}

None.

\section{Conflict of Interest}

No conflict of interest.

\section{References}

1. Dekker PA (2002) Epilepsy A manual for Medical and Clinical Officers in Africa. Revised edition. World Health Organization, Geneva.

2. Sridharan R (2002) Epidemiology of epilepsy. Current Science 82(6).

3. Gordon K, Camfield P, Camfield C, Smith E (1996) Discontinuation of anticonvulsant therapy in children free of seizure for 1 year: A prospective study. Neurology 46: 969-974.

4. Shinnar S, Vining EPG, Mellits ED (1985) Discontinuing antiepileptic medication in children with epilepsy after 2 years without seizures. N Engl J Med 313: 976-980.

5. Berg AT, Shinnar S (1994) Relapse following discontinuation of antiepileptic drugs: a metaanalysis. Neurology 44: 601-618.

6. Tennison M, Greenwood R, Lewis D, Thorn M (1994) Discontinuing antiepileptic drugs in children with epilepsy. N Engl J Med 330: 14071410.

7. Specchio LM, Tramacere L, La Neve A, E Beghi (2002) Discontinuing antiepileptic drugs in patients who are seizure free on monotherapy. J Neurol Neurosurg Psychiatry 72: 22-25.

8. Thurston JH, Thurston DL, Hixon BB, et al. (1982) Prognosis in childhood epilepsy. Additional follow-up of 148 children 15-23 years after withdrawal of anticonvulsant therapy. N Engl J Med 306: 831-836.

9. Medical Research Council Antiepileptic Drug Withdrawal Study Group (1991) Randomized study of antiepileptic drugs withdrawal in patients in remission. Lancet 337: 1175-1780.

10. Tinuper P, Avoni P, Riva R, Provini F, Lugaresi E, et al. (1996) The prognostic value of the electroencephalogram in antiepileptic drugs withdrawal in partial epilepsies. Neurology 47: 76-78.

11. Avoni P, Riva R, Tinuper P (1996) Prognosis of epilepsies in antiepileptic drugs discontinuation. Epilepsia 37(Suppl 4): 58-9.

12. Braathen G, Melander H (1997) Early discontinuation of treatment in children with uncomplicated epilepsy: a prospective study with a model for prediction of outcome. Epilepsia 38: 561-569.

13. Mastropaolo C, Tondi M, Carboni F, Manca S, Zoroddu F (1992) Prognosis after therapy discontinuation in children with epilepsy. Eur Neurol 32: 141-145.

14. BRITTON JW (2002) Antiepileptic Drug Withdrawal: Literature Review. Mayo Clin Proc 77(12): 1378-1388.

15. Shinnar S, Berg AT, Moshé SL, Kang H, O’Dell C, et al. (1994) Discontinuing antiepileptic drugs in children with epilepsy: a prospective study. Ann Neurol 35: 534-545.

16. Berg AT, Shinnar S (2001) Two-years remission and subsequent relapse in children with newly diagnosed epilepsy. Epilepsia 42: 1553-1562.

17. Tennison M, Greenwood R, Lewis D, Thorn M (1994) Rate of taper of antiepileptic drugs and the risk of seizure recurrence in children. $\mathrm{N}$ Eng J Med 330: 1407-1410.

18. Aldenkamp AP, Alpherts WCJ, Blennow G (1993) Withdrawal of antiepileptic medication in children effects on cognitive function: The multicenter Holfrid study. Neurology 43: 41-50. 